\title{
Safety parameters calibration in the structural design of sewer liners
}

\author{
Arkadiusz $\operatorname{Szot}^{1, *}$ \\ ${ }^{1}$ Wrocław University of Science and Technology, ul. Wybrzeże Wyspiańskiego 27, Wrocław, Poland
}

\begin{abstract}
The article concerns aspects of safety in the process of designing continuous polymer liners used to strengthen and seal sewers and drains. The issues of safety coefficients, the variability of basic loadbearing parameters of liners and the problem of sensitivity of analytical solutions describing load-bearing capacity are discussed. The currently used magnitude of safety factors has been verified. The results of an examination on the safety index of liners for strengthening sewers has been presented in the paper. The necessity for the verification of current concepts of liner safety normalisation was herein addressed. A postulation to abandon the analogy of liners for newly constructed pipes was formulated. Calculations using the Hasofer-Lind safety index (First Order Reliability Method) were performed in some cases. A verification and evaluation of the global safety factor for sewer liners were herein carried out.
\end{abstract}

\section{Introduction}

Reliability is now becoming the basic measure of long-term structural safety. In front of the decline of deterministic methods of estimating the load capacity of structures in favour of probabilistic and stochastic methods is observed. For many years, this tendency has been manifested by introducing the dimensioning of structural elements to modern algorithms through the use of various types of safety factors. Arbitrarily assumed safety measures are replaced by the resulting quantities from a probabilistic analysis of construction work.

The fact that the aspect of safety of lining reinforcing sanitary sewers was not fully examined, prompted the author to undertake a comprehensive analysis of the safety of this type of construction in the light of previous experience, laboratory tests and design algorithms. The rapid increase in the popularity of liner technology has made it so that the methods of their dimensioning were borrowed from the dimensioning algorithms of newlyinstalled underground pipes. However, the applied analogy turned out to be a false assumption and the need to develop new solutions arose. Over time, some methods of load capacity estimation departed from the assumptions of the analogy to installed pipes in excavations. However, the problem of liner safety has been transferred to new algorithms directly without a comprehensive examination of this aspect of new solutions. In order to ensure a reliable estimation of the load-bearing capacity of the lining constructions, it is

\footnotetext{
* Corresponding author: arkadiusz.szot@pwr.edu.pl
} 
therefore necessary to update existing algorithms with reliability aspects based on statistical data.

The current analysis is one of the first steps towards a more rational and safe dimensioning of the liners. The first step by the author was to estimate the so-called conventional global safety factor for the basic approach to the stability problem of liners [2]. The result of this analysis was the conclusion that the hitherto used safety factor values are too low for the high coefficients of variation of geometrical and mechanical parameters. This article presents the next step of a comprehensive reliability analysis based on the estimation of Hasofer-Lind reliability indexes using well-known basic load estimation algorithms and the results of laboratory tests carried out in various scientific centres $[1,10$, 14].

The Hasofer-Lind reliability index is an advanced and verified measure of safety based on selected probabilistic parameters of the structure. The advantage of this size is that it is not necessary to recognize all the characteristics of random variables describing the safety of the structure. Only basic parameters such as average value and standard deviation are sufficient for the analysis. Due to the ignorance of the function of the probability distributions of geometrical and mechanical parameters of liners, the most commonly observed normal distribution was assumed. Average values and standard deviations of geometrical and mechanical parameters were taken from the results of laboratory tests.

\section{Estimation of Hasofera-Lind index reliability}

The analysis assumes that all parameters affecting the load-bearing capacity of liners apply to the normal distribution. The same assumption was assumed for the boundary function. In addition, it was assumed that random variables are independent.

The general definition of the probability of failure:

$$
P_{f}=\operatorname{Pr}\{R<S\}=\operatorname{Pr}\{R-S<0\}=\operatorname{Pr}\{R / S<1\}
$$

where: $\mathrm{R}$ - random variable representing strength and $\mathrm{S}$ - random variable representing the load.

Formulation of the limit function:

$$
G(R, S):(R-S)=0
$$

Random variables are normalized to reduced variables by the following transformation:

$$
u_{i}=\frac{x_{i}-\mu_{i}}{\sigma_{i}}
$$

where: $u_{i}$ - i-ta normalized random variable, $x_{i}$ - i-th random variable, $\mu_{i}$ - average value $\mathrm{i}$-th random variable, $\sigma_{i}$ - standard deviation of $i$-th random variable.

The basic formula describing the snap-through stability under the action of groundwater lining installed in the sanitary sewer is as follows [2]:

$$
P_{c r}=E \cdot\left(\frac{t}{D}\right)^{2,2}
$$

where: $P_{c r}$ - critical peripheral ground water pressure, $t$ - liner thickness, $D$ - average diameter of the liner, $E$ - long-term elastic modulus of the liner. 
In the problem under consideration, the border function takes the following form:

$$
G\left(E, t, D, p_{w}\right)=E \cdot\left(\frac{t}{D}\right)^{2,2}-p_{w}=0
$$

where: $p_{w}$ - groundwater pressure at the level of the channel kinetics.

The reduced variables have the form:

$$
u_{1}=\frac{E-\mu_{E}}{\sigma_{E}}, u_{2}=\frac{t-\mu_{t}}{\sigma_{t}}, u_{3}=\frac{D-\mu_{D}}{\sigma_{D}}, u_{4}=\frac{h_{w}-\mu_{p_{w}}}{\sigma_{p_{w}}}
$$

where: $u_{i}$ - normalized random variables, $\mu_{E}$ - average modulus of elasticity, $\sigma_{E}$ standard deviation of the elastic modulus, $\mu_{t}$ - average thickness of the liner, $\sigma_{t}$ - standard deviation of liner thickness, $\mu_{D}$ - average diameter of the floor covering, $\sigma_{D}$ - standard deviation of the floor covering diameter, $\mu_{P w}$ - average ground water pressure, and $\sigma_{P w}$ standard deviation of groundwater pressure.

We can substitute for the formula (5) the following values resulting from the transformation of normalized random variables:

$$
E=\mu_{E}+u_{1} \cdot \sigma_{E}, t=\mu_{t}+u_{2} \cdot \sigma_{t}, D=\mu_{D}+u_{3} \cdot \sigma_{D}, h_{w}=\mu_{p_{w}}+u_{4} \cdot \sigma_{p_{w}}
$$

As a result, we get the following form of the limit function:

$$
G\left(u_{1}, u_{2}, u_{3}, u_{4}\right)=\left(\mu_{E}+u_{1} \cdot \sigma_{E}\right) \cdot\left(\frac{\mu_{t}+u_{2} \cdot \sigma_{t}}{\mu_{D}+u_{3} \cdot \sigma_{D}}\right)^{2,2}-\left(\mu_{p_{w}}+u_{4} \cdot \sigma_{p_{w}}\right)=0
$$

Determination of the Hasofer-Linda reliability index $\square$ comes to the solution of the following system of equations [8]:

$$
\begin{aligned}
& u_{i}^{*}=-\gamma_{i} \cdot \beta \\
& G\left(u^{*}\right)=0
\end{aligned}
$$

where:

$$
\gamma_{i}=\frac{\left[\frac{\partial G(u)}{\partial u_{i}}\right]_{u=u^{*}}}{\sqrt{\sum_{i=1}^{n=4}\left[\left(\frac{\partial G(u)}{\partial u_{i}}\right)^{2}\right]_{u=u^{*}}}}
$$

The above system of equations is a problem of non-linear optimization and requires calculation with the use of iterative methods. As a result of the calculations, we obtain the minimum value of the reliability index occurring at the most unfavorable combination of random variables. The Hasofer-Lind reliability index allows determining the cumulative function of the construction safety function, on the basis of which the probability of failure 
occurrence can be determined. The typical minimum value of the reliability index assumed in the calibration of standards is 4.26 , which corresponds to the probability of failure at the level of $10 \mathrm{e}-5$. In cases of structures with a higher level of consequences of failures, the reliability index increases even to 5.2, which corresponds to the probability of a failure of 10e-7. For typical structural engineering problems, the most frequently assumed reliability index is 4.26 [4]. An example of this may be recommendations [3].

The issue of the safety of floor coverings has not been investigated so far, and the level of safety factors in existing computational algorithms is adopted on the basis of an analogy to wires installed in the ground. In comparison to new sewer pipes, one should, however, expect a decrease in the level of reliability resulting from the greater variability of geometric and mechanical parameters and the lack of their control.

Table 1. Calculated Hasofer-Lind reliability indexes.

\begin{tabular}{|c|c|c|c|c|c|c|c|c|c|c|}
\hline \multirow{2}{*}{$\begin{array}{l}\text { exam. } \\
\text { prog./liner } \\
\text { type }\end{array}$} & \multicolumn{2}{|c|}{$\begin{array}{c}\text { diameter } D \\
{[\mathrm{~mm}]}\end{array}$} & \multicolumn{2}{|c|}{$\begin{array}{c}\text { wall thickness } \\
t \\
{[\mathrm{~mm}]} \\
\end{array}$} & \multicolumn{2}{|c|}{$\begin{array}{c}\text { Modulus of } \\
\text { elasticityi } E \\
{[\mathrm{MPa}]}\end{array}$} & \multicolumn{4}{|c|}{$\begin{array}{c}\text { reliability index H-L for } \\
\text { following water head level } \\
\text { above invert }\end{array}$} \\
\hline & aver & $\begin{array}{l}\text { std } \\
\text { dev }\end{array}$ & aver & $\begin{array}{l}\text { std } \\
\text { dev }\end{array}$ & aver & std dev & $2 \mathrm{~m}$ & $3 \mathrm{~m}$ & $4 \mathrm{~m}$ & $5 \mathrm{~m}$ \\
\hline $\begin{array}{c}\text { Guice et al } \\
\text { Inliner }\end{array}$ & 303,45 & 0,73 & 7,00 & 0,48 & 2018,35 & 188,03 & 4,68 & 4,46 & 4,23 & 4,01 \\
\hline $\begin{array}{l}\text { Guice et al } \\
\text { Insituform } \\
\text { Std. }\end{array}$ & 303,11 & 0,31 & 5,98 & 0,25 & 3093,17 & 132,93 & 8,33 & 7,92 & 7,52 & 7,14 \\
\hline $\begin{array}{l}\text { Guice et al } \\
\text { Insituform } \\
\text { Enh. }\end{array}$ & 303,91 & 0,44 & 5,73 & 0,12 & 3713,66 & 195,98 & 7,96 & 7,66 & 7,37 & 7,07 \\
\hline $\begin{array}{l}\text { Guice et al } \\
\text { NuPipe }\end{array}$ & 301,75 & 2,93 & 9,68 & 0,08 & 2650,70 & 154,72 & 8,17 & 8,04 & 7,92 & 7,80 \\
\hline $\begin{array}{l}\text { Guice et al } \\
\text { Paltem HL }\end{array}$ & 303,28 & 0,00 & 6,44 & 0,02 & 2018,79 & 88,02 & 7,90 & 7,49 & 7,07 & 6,66 \\
\hline $\begin{array}{l}\text { Guice et al } \\
\text { KM Inliner }\end{array}$ & 302,94 & 0,53 & 4,94 & 0,15 & 1948,52 & 184,80 & 3,49 & 3,10 & 2,72 & 2,34 \\
\hline $\begin{array}{l}\text { Guice et al } \\
\text { Superliner }\end{array}$ & 303,28 & 0,67 & 5,86 & 0,13 & 12306,56 & 3367,31 & 1,79 & 1,77 & 1,76 & 1,76 \\
\hline $\begin{array}{l}\text { Aggarwal et } \\
\text { al Epoxy } \\
250 / 99 \text { P\&S }\end{array}$ & 251,64 & 0,89 & 5,27 & 1,57 & 2215,71 & 161,23 & 2,11 & 1,93 & 1,76 & 1,61 \\
\hline $\begin{array}{l}\text { Aggarwal et } \\
\text { al Poly } 405\end{array}$ & 248,02 & 3,39 & 5,03 & 0,55 & 1800,50 & 389,28 & 2,00 & 1,86 & 1,72 & 1,58 \\
\hline $\begin{array}{l}\text { Aggarwal et } \\
\text { al Derakane }\end{array}$ & 250,83 & 1,68 & 5,42 & 1,69 & 1458,83 & 162,11 & 1,80 & 1,60 & 1,41 & 1,24 \\
\hline $\begin{array}{c}\text { Aggarwal et } \\
\text { al } 4168.00\end{array}$ & 250,24 & 0,85 & 6,62 & 2,24 & 2117,00 & 268,42 & 2,08 & 1,94 & 1,82 & 1,71 \\
\hline $\begin{array}{l}\text { Aggarwal et } \\
\text { al Synres }\end{array}$ & 249,76 & 1,43 & 5,54 & 2,01 & 1569,17 & 348,85 & 1,96 & 1,42 & 1,26 & 1,12 \\
\hline Wagner 250 & 247,90 & 3,69 & 5,60 & 1,01 & 2690,09 & 529,96 & 2,36 & 2,27 & 2,18 & 2,09 \\
\hline Wagner 300 & 295,42 & 3,83 & 8,87 & 1,00 & 2863,63 & 195,11 & 6,25 & 6,03 & 5,82 & 5,61 \\
\hline
\end{tabular}

In order to verify the level of security provided by the existing calculation algorithms, a number of calculations of reliability indicators were carried out. Statistical data describing the geometrical and mechanical parameters of the liners necessary to carry out the calculations were taken from the results of laboratory tests $[1,10,14]$. Characteristic levels of groundwater affecting the floor covering were assumed as for the most common, real design cases, i.e. 2, 3, 4, and $5 \mathrm{~m}$ above the channel kinetics. Calculations of the HasoferLind reliability index were carried out for individual design issues. The results of calculations are presented in Table 1 . 
Analyzing the presented results, one can conclude that the reliability index is not directly determined by the average values of geometrical and mechanical parameters and their standard deviations are definitely greater. This aspect is not directly taken into account in any of the author's known load capacity estimation algorithms. A typical scheme for considering the safety of liner constructions is the unified global safety factor, which does not take into account the specificity of the material. The observed phenomenon is proof of the need to include partial safety coefficients for particular parameters in calculation algorithms.

The presented calculation results were performed for various existing laboratory tests results, they do not constitute a basis for comparing different material solutions in terms of their reliability. Different diameters and wall thicknesses of floor coverings were used. The results presented for individual solutions do not correspond together. However, the calculations carried out give a picture of the behavior of reliability indexes in the scope of the applicability of floor coverings.

Another conclusion is to be found when analyzing declines in the size of reliability indicators together with groundwater level increase (Figure 1). It is characteristic that this decrease takes place approximately linearly, but the gradient is variable for particular types of floor coverings. It can be concluded that if the linear decrease in the index would indicate the possibility of using a global safety factor in the computational algorithm, the variable gradient characteristic for the material makes the global safety factor not a universal factor of safety regulation.

\section{Example of estimating the bearing capacity of a liner, taking into account the reliability aspect}

To determine the significance of considering the reliability aspect in liner design, calculating the reliability index for a specific project task was carried out. The data used as part of the design workshops, which took place during the Underground Infrastructure Research conference [6, 12], were accepted. The case of canal reinforcement was considered there with a resin lining with imposed geometrical and mechanical parameters. The aim of the workshop was to determine the thickness of the liner ensuring construction safety by any method of load capacity estimation. A design example is shown in Fig. 2. The average thickness of the liner obtained from the calculations carried out with several methods was $14.5 \mathrm{~mm}$, and the range of this size ranged from 10.7 to $22.0 \mathrm{~mm}$.

Assumed parameters:

sewer diameter DN800

liner material: polyester resin

liner modulus of elasticity: short term $3000 \mathrm{~N} / \mathrm{mm}^{2}$, long term $1500 \mathrm{~N} / \mathrm{mm}^{2}$

bending strength: long term $20 \mathrm{~N} / \mathrm{mm}^{2}$

compressive strength: long term $40 \mathrm{~N} / \mathrm{mm}^{2}$

Poisson's ratio: $\mathrm{v}=0,35$

ground modulus of elasticity $\mathrm{E}_{\mathrm{s}}=10 \mathrm{MN} / \mathrm{m}^{2}$

unit weight $\mathrm{y}=19 \mathrm{kN} / \mathrm{m}^{3}$

rate of compaction $\mathrm{D}_{\mathrm{Pr} .}=90 \%$ 


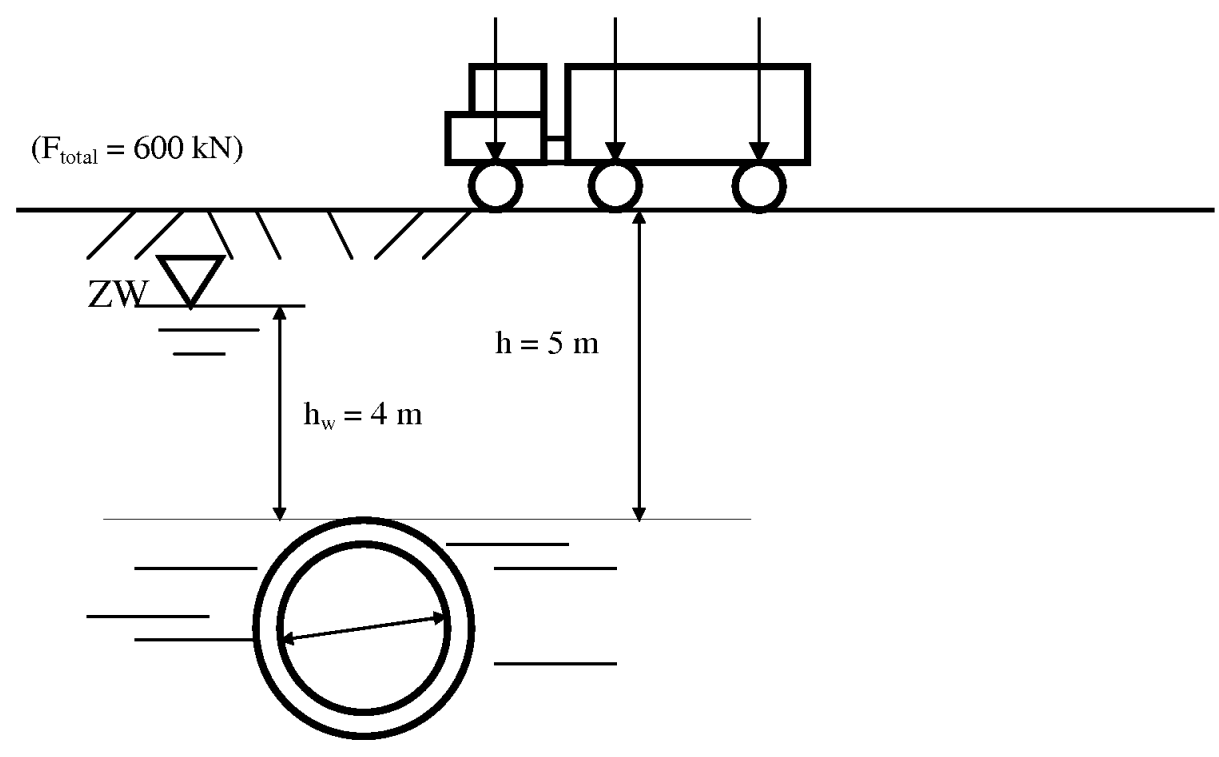

Fig. 1. Load configuration.

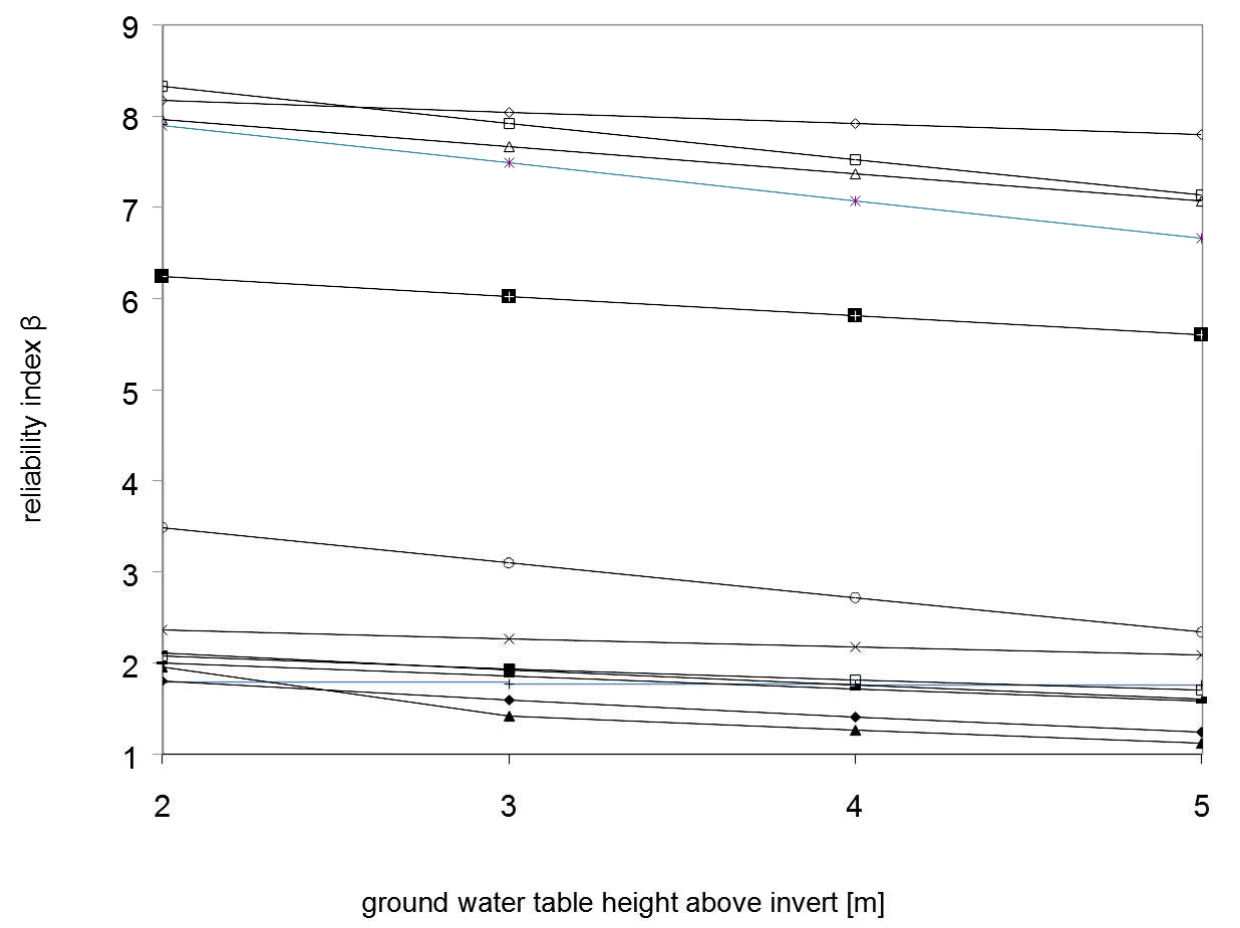

Fig. 2. Calculated Hasofer-Lind index vs ground water table height.

In the current analysis, an estimation of the necessary thickness of the liner was carried out including reliability by striving to achieve a reliability index of 4.26 corresponding to the minimum commonly accepted probability of failure. Statistical data describing random variables of diameter, wall thickness and the modulus of elasticity were estimated on the 
basis of [8]. These data have been developed based on floor coverings made in real conditions. So you may think that they reflect the most reliable parameters. The following values of mean values and standard deviations were adopted: $\mu_{\mathrm{E}}=1500 \mathrm{MPa}, \sigma \mathrm{E}=300$ $\mathrm{MPa}, \mu_{\mathrm{D}}=782 \mathrm{~mm}, \sigma_{\mathrm{t}}=1 \mathrm{~mm}, \sigma_{\mathrm{D}}=6 \mathrm{~mm}, \mu_{\mathrm{Pw}}=48 \mathrm{kPa}, \sigma_{\mathrm{Pw}_{\mathrm{w}}}=10 \mathrm{kPa}$. The size of $\mu \mathrm{t}$ was variable and constituted an optimization parameter to achieve the appropriate reliability index.

From the performed calculations, $4.26 \mu_{\mathrm{t}}=18 \mathrm{~mm}$ was obtained for the reliability index 4.26. This means that this value should be taken as the thickness of the lining ensuring the desired level of safety. The obtained quantity is significantly higher than the average calculated by classical analytical and numerical methods [6] [12]. On the basis of the performed calculations, the value of the global safety factor, which is defined for the Hasofer-Lind procedure as [4], was also estimated:

$$
\gamma_{s}=\frac{s^{*} \cdot r_{k}}{r^{*} \cdot s_{k}}
$$

where: $\gamma_{\mathrm{s}}$ - global safety factor, $\mathrm{s}^{*}$ - load size as the coordinate corresponding to the calculated reliability index, $\mathrm{s}^{*}$ - load capacity as the coordinate corresponding to the calculated reliability index, $\mathrm{r}_{\mathrm{k}}$ - characteristic load capacity, $\mathrm{s}_{\mathrm{k}}$ - characteristic load size.

The calculated values using the nominal values of the component parameters, i.e. the diameter of the liner $\mathrm{D}=800 \mathrm{~mm}$, the modulus of elasticity $\mathrm{E}=1500 \mathrm{MPa}$, wall thickness $\mathrm{t}$ $=18 \mathrm{~mm}$, groundwater pressure $\mathrm{p}_{\mathrm{w}}=48 \mathrm{kPa}$, were assumed to be characteristic values. The global safety factor calculated according to formula 12 was 2.89 . It is a size significantly higher than that used in existing calculation algorithms. This confirms the thesis about the need to increase the safety factor previously set in [11].

\section{SUMMARY}

The article presents the basic results of the analysis of the safety of sewer liners. The size of reliability indexes associated with the selected real practical applications were estimated. The current security level implemented in existing load estimation algorithms for these structures has been examined. It has been suggested using far higher safety factors resulting from the high variability of geometric and mechanical parameters. Ultimately, it is advisable to move away from the concept of a global safety factor in favor of partial factors. This will allow a more rational and safer design of floor coverings. The obtained results show that existing load estimation algorithms require verification and recognition of reliability aspects. It is necessary to definitively abandon mechanical analogies for newlyinstalled wires. Research on the mechanical aspects of floor coverings indicates a completely different nature of the work of these structures. The use of such an analogy leads to a lowering of the level of safety, as evidenced by the current research.

\section{References}

1. S.C. Aggarwal, M.J. Cooper, External pressure testing of Insituform lining, raport wewnętrzny, Coventry Polytechnic, Coventry (1984)

2. DWA-A 143-2, Sanierung von Entwässerungssystemen außerhalb von Gebäuden. Teil

2: Statische Berechnung zur Sanierung von Abwasserleitungen und -kanälen mit Lining- und Montageverfahren, DWA regelwerk (2015) 
3. ATV-DVWK A127, Richtlinie für die statische Berechnung von Abwasserkanälen zur Sanierung von Abwasserkanälen und -leitungen mit Lining- und Montageverfahren, GFA Verlag, Hennef (2000)

4. A. Biegus, Podstawy probabilistycznej analizy bezpieczeństwa konstrukcji, Oficyna Wydawnicza Politechniki Wrocławskiej, Wrocław (1996)

5. S. Bin, Reliability-based optimization of anisotropic cylinders with response surface approximation of axial buckling load, dysertacja, Mississippi State University (2001)

6. J. Boot, I. Doherty, B. Falter, J. Gumbel, D. Hall, A. Hoch, I. Moore, H. Niemann, H. Romdal, A. Szot O. Thepot, Workshop - International Liner Design Comparison, not published, conference Underground Infrastructure Research, Kitchener (2001)

7. B. Bosseler; M. Schlüter, Qualitätseinflüsse Schlauchliner Stichproben-Untersuchung an sanierten Abwasserkanälen, Raport IKT - Institut für Unterirdische Infrastruktur, GEK mbH, Gelsenkirchen (2003)

8. O. Ditlevsen, H.O. Madsen, Structural Reliability Methods, John Wiley \& Sons Ltd, Chichester (1996)

9. M.H. Faber , J.D. Sorensen, Reliability Based Code Calibration, Raport Joint Committee on Structural Safety (2002)

10. L.K. Guice, T. Straughan, C. Norris, R. Bennett, Long-term structural behaviour of pipeline rehabilitation systems, Trenchless Technology Center Raport, Louisiana Tech University, Ruston (1994)

11. A. Szot, Podstawowe problemy bezpieczeństwa w projektowaniu wykładzin kanałów sanitarnych, IX Conference Underground Urban Infrastructure Wrocław 2006, Dolnośląskie Wydawnictwo Edukacyjne, Wrocław, 433-438 (2006)

12. O. Thepot, International comparison of methods for the design of sewer linings, $3 \mathrm{R}$ International, 8-9, 520-526 (2004)

13. I.J.J. van Straalen, Development of design rules, Raport of the DOGMA project, www.dogma.org.uk (1999)

14. V. Wagner, Beulnachweis bei der Sanierung von nichtbegehbaren, undichten Abwasserkanälen mit dem Schlauchverfahren, dissertation, Uniwersytet Techniczny, Berlin (1992) 